\title{
Evaluation of individual quality of life among hemodialysis patients: nominated themes using SEIQoL-adapted
}

\section{Hossein Matlabi \\ Sharareh Ahmadzadeh}

Department of Health Education and Promotion, Faculty of Health Sciences, Tabriz University of Medical Sciences, Tabriz, Iran
Correspondence: Hossein Matlabi Department of Health Education and Promotion, Faculty of Health Sciences, Tabriz University of Medical Sciences, Attare Neishabouri St, Tabriz, PO Box 51656658II, Iran Tel +98 9| 4l 008927

Fax +98 4l 3334473 I

Email.hm1349@gmail.com
This article was published in the following Dove Press journal:

Patient Preference and Adherence

16 December 2016

Number of times this article has been viewed

Background: Quality of life (QoL) has become an important issue for patients with chronic renal failure diseases who are permanently undergoing hemodialysis. In this study, an adapted schedule for the evaluation of individual quality of life (SEIQoL-adapted) was used to evaluate QoL among hemodialysis patients, to explore their views about the most important aspects of life satisfaction. Methods and results: A multiple approach design and convenience sampling were applied to recruit 53 patients from a hemodialysis unit in Iran. Data were collected through structured interviews and then analyzed using conventional content analysis. A total score for QoL was calculated using scale guideline. The most important aspects of life were health, family, financial status, living conditions, leisure activities, relationships and socializing, religious and spiritual issues, medical knowledge, and therapies or treatments. The calculated mean QoL score was 66.2, indicating a relatively high life satisfaction. Males had higher QoL scores than females in both married and single groups. Moreover, the relationships between the QoL scores and education, job and marital status were not statistically significant.

Conclusion: The SEIQoL-adapted revealed reasonable lay definitions of QoL in a group of patients following chronic renal failure. The patients' views of the aspects of life could be used by health policy makers, clinicians, and caregivers as a reliable guide to the most important priorities for treatment and medical interventions.

Keywords: quality of life, SEIQoL-adapted, renal dialysis

\section{Introduction}

According to World Health Organization (WHO), quality of life (QoL) is defined as "individuals' perception of their position in life in the context of the culture and value systems in which they live and in relation to their goals, expectations, standards and concerns." This is a mainly comprehensive definition but indicates that QoL is a rather subjective experience. The challenging perception of QoL is that it is presented virtually for everyone and all academic disciplines, but it is expressed differently for each person and each organization. ${ }^{2}$

It has been indicated that patient self-assessment instruments for assessing QoL are far more accurate than standard assessment instruments designed by healthcare professionals. $^{3}$ For instance, the kidney disease quality of life and the 36-item short form health survey contain a list of predetermined questions but may not completely express individual's perceptions. Although these measures may be reliable, they may not be relevant to an individual's present life situation., ${ }^{4,5}$

In the past few years, many methods have been designed substantially for assessing subjective QoL perceptions. These methods have placed the patient at the center of 
decision-making and increased interest in healthcare from the consumer perspective. ${ }^{6}$

The schedule for the evaluation of individual quality of life (SEIQoL) helps the medical staff understand patients' views about health, performance capacities, sense of welfare, and the benefits of treatment procedures. Particularly, special and continuous attention is required for patients experiencing hemodialysis treatments due to their multiple medical procedures and special nutrition needs. Furthermore, chronic renal failure patients require particular skills while facing physical and mental difficulties. ${ }^{7,8}$

The SEIQoL is a multifaceted measure of a complex process and its use in routine clinical situations may prove impractical. ${ }^{9}$ An abbreviated form of the measure, the SEIQoL-direct weighting (SEIQoL-DW) is an individualized measure of a professed QoL based on interview which replaces the more cumbersome judgment analysis technique with a simpler procedure for measuring the relative importance (weights) to the respondent of scheduled life areas. ${ }^{10}$ The SEIQoL-DW has been previously validated against the full version of the SEIQoL and has been indicated as a valid and reliable measure for assessing QoL domains. ${ }^{11-14}$

However, administering the SEIQoL-DW for delicate patients such as older people and less-educated clients is accompanied with several limitations. ${ }^{12}$ Also, its applicability is limited to illnesses in which cognitive functioning or motivating state is impaired such as patients with impaired vision and lack of manual dexterity. ${ }^{13}$ Moreover, completing the entire tool is time consuming (mean time $\sim 38$ minutes), and many participants become confused or exhausted at the second and third stages. ${ }^{12}$ Finally, successful completion is difficult for chronically ill patients because the instrument requires sufficient levels of insight and speed of action that many cannot succeed. ${ }^{14-16}$

The present study used a modified second and third stages of the SEIQoL-DW to replace the cumbersome judgment analysis technique with a simpler procedure for weighting the relative importance of the respondent's nominated life areas. ${ }^{17,18}$ Scoring instructions for the SEIQoL-adapted is based on the article by Hickey et al (1996). ${ }^{12}$ Participants are required to choose five domains of significance for their QoL and then rank those domains instead of weighting them and eventually rate their current level of satisfaction with each domain on a 4-point Likert scale (very satisfied, satisfied, dissatisfied, or very dissatisfied). QoL scores are calculated by summing the entire ranks and satisfaction ratings for each domain and presenting a score, ranging from 25 to 100 . Higher scores represent higher QoL. ${ }^{17,18}$
Evaluation of the individual dialysis patient's QoL may help doctors and nurses design and implement care strategies that are in accordance with the patient's values and needs. More importantly, developing an understanding of both the patient's fears and their views about their needs and desired services may enable the psychological aspects of well-being to be more effectively addressed, as by strengthening the social support network and providing guidance on how to cope with depression. ${ }^{3}$

Maximizing patient function and well-being and reducing morbidity and mortality should be important priorities in hemodialysis settings. All healthcare professionals who provide holistic care for patients, particularly patients with chronic illness such as renal failure should deeply deliberate on QoL and address their needs more effectively. ${ }^{3}$ This study reports the key findings of analyses that investigated the views of chronic renal failure patients about most important aspects of life and satisfaction rate.

\section{Materials and methods Design}

The study used multiple approaches. First, using a descriptive correlational study design, the most important aspects of life and satisfaction rate were investigated. Second, nominated themes were explicitly categorized using conventional content analysis method.

\section{Sampling and participants}

A convenience sampling method was used during 2014-2015 to recruit 53 patients who were eligible among 102 patients in the central and referral hemodialysis unit at AmirAlmomenin hospital in Maragheh, $\operatorname{Iran}(\beta=0.87)$. These samples had filed cases in this center and had undergone dialysis for 4 hours twice or thrice per week; furthermore, at least 1 year had passed from outset of their first dialysis. These patients were selected regardless of age, sex, family and cultural characteristics, location of living, and other features.

\section{Exclusion criteria}

Patients were excluded from the study if they had hearing and speech problems, unrelated kidney failure diseases (terminally ill patients, cardiovascular diseases, and diabetes), severe mental health problems (pre-admission screening) or had been undergoing treatment for $<1$ year.

\section{Procedure}

The hemodialysis unit manager provided eligible patents with information about the study. Interview dates were 
arranged and patients were contacted for availability. The interview periods were based on patient situation and incorporate all maximum time periods $(\sim 10-15$ minutes). The required information was collected primarily through individual interviews and the instrument-based questions in private (see Supplementary material for the details of the three-stage process). Interviews were conducted by a trained and experienced nurse who is working in the hemodialysis unit. Probing questions were used to explore the basis of the patents' responses. An assistant was present at all interviews, in order to take notes and observe nonverbal reactions and communications. All the interviews were fully audio-recorded.

\section{Measures}

The SEIQoL-adapted scale ${ }^{17,18}$ and socio-demographic questions were used to collect data. The total QoL score as well as the patients' viewpoints were gathered using the scale guidelines. This measure derives from a structured interview that asks participants to nominate life domains that they consider as important to their own life and weigh up their relative importance and their current level of satisfaction with each domain. ${ }^{17}$ The score can range from 25 (lowest QoL) to 100 (highest). A further detail of the procedure for administering the SEIQoL-adapted is described in Supplementary material.

\section{Analysis}

The relationships between the QoL score and income status, educational level, social life, and family support were investigated using difference of means tests and analysis of variance.

Data analysis started with reading all data repeatedly by two researchers independently to achieve immersion, obtain a sense of the whole, and derive codes. Based on Lincoln and Guba's evaluative criteria, credibility, transferability, dependability, and confirmability issues were investigated to evaluate the validity and reliability of the results and the objectivity of the study. ${ }^{19}$

\section{Ethical considerations}

All procedures performed in study were in accordance with the ethical standards of, and approved by the Tabriz University of Medical Sciences Institutional Review Board (approval no: 5/4/4870-20/08/2014). Informed consent was obtained from all participants. Each patient's right to withdraw from the study at any stage and the confidentiality of their responses was emphasized.

\section{Status of hemodialysis patients in Iran}

In Iran, the patients undergo dialysis for 12 hours thrice per week, whereas in some other countries, this duration is $\sim 20-25$ hours. ${ }^{20}$ The cultural conditions and the pudency which is specific to the Iranian and Eastern societies prevent the patients, especially females, from expressing their problems; this can lead to intensify the mental problems in the patients. Furthermore, it is not possible to provide all services in the form of health insurance in the public sector. This causes a gap between the services provided by insurance companies and the real needs of patients.

\section{Results \\ Participants' characteristics}

The study sample comprised 53 patients (31 males and 22 females). The mean age was 54 years (minimum 22 years and maximum 80 years). All the participants had been treated for $>1$ year. About two-thirds of the patients were living in the city and 46 (86.8\%) were married. In terms of educational status, the majority of the participants were illiterate (71.7\%) and none had an academic degree. Furthermore, the majority was unemployed or disabled and only five had jobs. All the patients indicated that they were in the lower income category. In fact, almost one-half earned $<160$ US dollars per month. The patients' partners were the main caregivers in $50 \%$ of the cases.

\section{Main domains of QoL: viewpoints of participants}

Based on the user guide of the SEIQoL-adapted scale, the QoL score for every participant was calculated. ${ }^{17,18}$ Not all of the participants provided five items ( $83 \%$ five items, $13 \%$ four items, and $4 \%$ three items). The responses concerning the most important aspects of one's life were very diverse. All the answers were categorized into the eight main clusters of health, family, financial status, living condition, leisure and entertainment activities, relationships, religious-spiritual issues, and medical knowledge and treatment procedure. Health issues were the only theme and category that most of participants referred to as a fundamental concern during their illness. Nearly two-third of the participants declared that health is the first priority in their life. Moreover, 19\% and $15 \%$ of the participants regarded health as the second and the third priority in their life, respectively. The predominant viewpoints of the patients are summarized in Table 1.

\section{Total scores of QoL and satisfaction rate}

The SEIQoL-adapted scores ranged from 25 to 100 (higher scores indicating better QoL). The minimum score was 27 
Table I Respondents' views and statements on important matters to their quality of life $(n=53)$

\begin{tabular}{lll}
\hline Theme & Frequency & Example statements and views \\
\hline Health & 52 & $\begin{array}{l}\text { Well-being; happiness; independent; autonomy; not ill; as the healthy life; } \\
\text { energy or vitality, do not use medical prosthetics such as a walker } \\
\text { Children are married; good intergenerational relations; marital satisfaction; } \\
\text { having children and grandchildren; healthy children; future of children; } \\
\text { happiness of children; family help; care, and supports }\end{array}$ \\
$\begin{array}{lll}\text { Wealth and money; high and appropriate income; unemployment } \\
\text { Financial status }\end{array}$ & 49 & $\begin{array}{l}\text { insurance; easy and best paying job; financial independence, stability of job, } \\
\text { agricultural sustainability and intensive production, and stable salary }\end{array}$ \\
Living conditions & 34 & $\begin{array}{l}\text { Expensive furniture; affordable housing; living in high-class areas; having a } \\
\text { valuable car; a decent life, and life situation }\end{array}$ \\
Leisure activities & 20 & $\begin{array}{l}\text { Hiking; traveling; gardening; social events with family members and } \\
\text { neighbors; and watching free satellite channels }\end{array}$ \\
Relationships and socializing & 13 & $\begin{array}{l}\text { Social security; happiness around family members; peace at home and } \\
\text { family; having a friend; having a care-giver; helping others; love; effective } \\
\text { care; and communication of dialysis staff } \\
\text { Believing in God; pilgrimage to Mecca and Karbala; and praying to God } \\
\text { Having a high education; children's education; knowledge about restrictions }\end{array}$ \\
Religious and spiritual issues & in diet, activities, and life style; mood of staff; physical and emotional \\
Medical knowledge and & situation of dialysis department; and welfare conditions of the department \\
treatment procedure & 17 &
\end{tabular}

and the maximum was 100 . The mean was 66.2 and the standard deviation 18 . The patients were most satisfied with their QoL in the domains of family and religious and spiritual issues. They were least satisfied with their medical knowledge, the therapy or treatment they received, their financial status, and their leisure activities. The distribution of scores is presented in Figure 1.

\section{The relationship between QoL and socio- demographic characteristics}

The specific independent $t$-test and analysis of variance showed that there was no significant difference between the

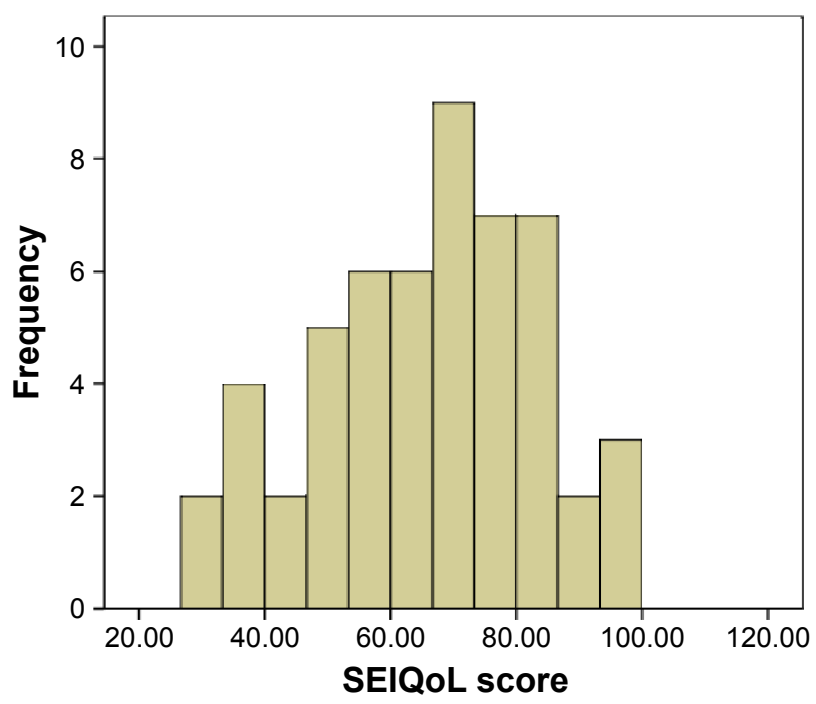

Figure I The distribution of SEIQoL-adapted scores.

Abbreviation: SEIQoL-adapted, an adapted schedule for the evaluation of individual quality of life.
QoL means and the educational level $(P=0.28)$, employment status $(P=0.86)$, financial status $(P=0.84)$, gender $(P=0.23)$, residence area $(P=0.65)$, and treatment period $(P=0.64)$. Interestingly, married patients who received higher levels of support from their partner reported higher QoL scores [marital status $(P=0.03)$ and career $(P=0.05)]$. The QoL was also higher among males than females in both married and single groups, and the total QoL score was higher among the retired patients than the others. The relationship between QoL and sociodemographic variables are summarized in Table 2.

\section{Discussion}

Due to technological advancements in healthcare and specifically hemodialysis, recently there have been reductions in side effects such as hypotension, cramps, dizziness, and nausea during the dialysis sessions. However, the issue of patients' welfare during the treatment and in their daily life can be improved further by focusing on their perceptions of QoL. ${ }^{21}$

A research in Brazil assessed dialysis patients' QoL. The study criticized healthcare professionals who disregarded the patients' feelings about their well-being, their perceptions, and their views about medical procedures. ${ }^{22}$ Nowadays, health staff should be trained to administer the QoL subjective measures and to use them to improve the well-being of their patients. It should be remembered that kidney failure disease reduces patients' QoL more than heart failure, diabetes, chronic lung disease, and cancer. $^{22,23}$ 
Table 2 Relationship between quality of life and sociodemographic variables $(n=53)$

\begin{tabular}{|c|c|c|c|}
\hline Variable & Mean & SD & $P$-value \\
\hline \multicolumn{4}{|l|}{ Sex } \\
\hline Male & 68.7 & 17.5 & \multirow[t]{2}{*}{$0.23 *$} \\
\hline Female & 62.6 & 18.4 & \\
\hline \multicolumn{4}{|l|}{ Marital status } \\
\hline Single & 63.1 & 16.1 & \multirow[t]{2}{*}{$0.03 *$} \\
\hline Married & 71.8 & 20.8 & \\
\hline \multicolumn{4}{|l|}{ Residence area } \\
\hline Urban & 65.4 & 18.7 & \multirow[t]{2}{*}{$0.65^{*}$} \\
\hline Rural & 68.0 & 16.6 & \\
\hline \multicolumn{4}{|l|}{ Employment status } \\
\hline Employed & 67.6 & 10.6 & \multirow[t]{4}{*}{$0.86^{\#}$} \\
\hline Unemployed & 64.4 & 16.8 & \\
\hline Retired & 70.6 & 16.9 & \\
\hline Disabled & 66.2 & 23.6 & \\
\hline \multicolumn{4}{|l|}{ Educational level } \\
\hline Illiterate & 64.5 & 17.3 & \multirow[t]{2}{*}{$0.28 *$} \\
\hline Literate & 70.5 & 19.4 & \\
\hline \multicolumn{4}{|l|}{ Treatment period } \\
\hline$>$ I year & 65.3 & 17.2 & \multirow[t]{2}{*}{$0.64 *$} \\
\hline$>5$ years & 67.7 & 19.7 & \\
\hline \multicolumn{4}{|l|}{ Career } \\
\hline Husband/wife & 72.3 & 16.2 & \multirow[t]{4}{*}{$0.05^{\#}$} \\
\hline Children & 64.2 & 21.4 & \\
\hline Father/mother & 57.2 & 18.2 & \\
\hline Self-care & 57.0 & 7.2 & \\
\hline \multicolumn{4}{|l|}{ Financial status } \\
\hline$<160 \$$ & 65.8 & 17.9 & \multirow[t]{2}{*}{$0.84 *$} \\
\hline $160-320 \$$ & 66.5 & 18.4 & \\
\hline
\end{tabular}

Notes: *P for independent $t$-test; ${ }^{*} P$ for analysis of variance.

With regard to the participants' view about very important items in their QoL, the analysis of responses to the SEIQoL-adapted instrument indicated that eight themes and main domains characterized the patients' self-reports. These domains were health issues, family, financial status, living conditions, leisure activities, relationships and socializing, religious and spiritual issues, medical knowledge, and procedures or treatments. Since all the participants mentioned health as the most important aspect of life, it seems that health in its general and specific aspects is the most important daily concern among hemodialysis patients. The QoL among patients with chronic renal failure was studied by Abdel-Kader et al using the SEIQoL. ${ }^{14}$ The participants mentioned a number of QoL domains such as family, health, job, school, leisure, and spirituality, among which health and family had the most frequency. It seems that renal function and general health were the most important influences on the QoL.

Returning to the results, family issues were reported as the next important factor in QoL: only $6 \%$ of the patients did not mention family as a main domain. Frequently used statements about family concerns included: my children have a good husband/wife, I enjoy good intergenerational relations,
I have a good husband/wife, I have supportive children and grandchildren, and my children are healthy. There were also many statements about their children's future, their children's happiness, and family help, care, and support. A review of QoL studies indicates that, as with kidney failure patients, those with other conditions cite family as the most important aspect of their life with the highest frequency. ${ }^{3}$

Wettergren (2002) investigated QoL among the patients suffering from a blood disorder. ${ }^{24}$ The participants were evaluated by five well-known standardized questionnaires measuring health-related aspects of life quality, a novel individualized measure, as well as the SEIQoL-DW. The results showed that $>50 \%$ of the patients mentioned family as the main life influence. Additional priorities were categorized as health, job, and their relationships with others. Compared with the control group, the patients who had experienced lymphoma for $>5$ years reported their QoL to be at a good level. ${ }^{24}$ Felgoise et al (2009) also measured the QoL among amyotrophic lateral sclerosis patients using SEIQoL-DW. Ninety percent of the participants indicated family as the most important influence, and other frequently cited domains were entertaining, leisure, and friends. ${ }^{13}$

Furthermore, individual QoL of 180 patients with prostate cancer was evaluated in the UK using the SEIQoL-DW. ${ }^{25}$ The patients cited 144 separate QoL concerns, which were then grouped into 13 different themes independently by three of the authors. The most frequently acknowledged themes were "leisure and hobbies," "family," and "health," which again evinced the important and supportive role of the family, especially spouse and children. The relationship between the family and a higher QoL was also significant. Moreover, it was found that life satisfaction and psychological wellbeing depended on the happiness of family members and a companionable spouse. ${ }^{25}$

Majority of the participants in the present study mentioned the importance of appropriate income in their life. Financial support of patients with chronic disease and their families by the government and charity organizations may play an important role in improving the life quality of these patients.

Overall, patients undergoing dialysis treatments require multiple medical procedures and a special diet that require close and continuous monitoring. They also need concerted help to acquire the skills they need to cope with their physical and mental difficulties. Renal clinics would have staff available to address the psychosocial aspects of patient well-being. Moreover, the information elicited by the SEIQoL-adapted should be useful for planning patient discharge and follow-up. 


\section{Limitations and weaknesses of the project}

Life quality assessment using SEIQoL has special features and is different from most of the studies of the QoL in that it investigates the mental and psychological aspects of people's lives. Generally, individuals will admit to others their physical problems more readily than their mental or psychological problems. Moreover, it is difficult for some people to articulate their wishes, desires, and hidden secrets. Age and cultural differences as well as particular ethnic prejudices are also involved in this regard. Another obstacle for responding to the interviewers' questions was modesty and prudence of some people. Lack of sufficient patience for an interview, especially among dialysis patients and older people were among other limitations of this study. To collect data in future studies, it is recommended to select interviewers of the same gender as the interviewees. Allocating more interview sessions is a prerequisite for the accurate expression of the wishes and interests of participants. Selecting a questioner who has training in psychology science is likely to raise the rigor of the study.

\section{Strengths and application of the project}

In the present study, since the interviewer was among the medical personnel and care-givers of dialysis patients, the participants had sufficient trust in her, which raised the interest of the participants in responding to the questions, thereby enhancing the validity of the study. It is recommended for the replicate studies to select interviewers from among the patients' trusted caregivers. The results of this study can be generalized to other patients hospitalized in hemodialysis centers across the country because majority of the patients were at the same age and educational range and belonged to the low-income group (except for few who avoided mentioning their exact income, probably because of social reasons and because they received government benefits).

The results demonstrated that, because of the high respect for family status in the Iranian society, that patients benefit from a good family support and that their most important life concerns are physical and mental health problems. Poor economic conditions and low income intensify the problems of many. The results could be used to ameliorate the problems that currently accompany dialysis. Also, it is necessary for the relevant authorities to plan or increase insurance for therapeutic support and to reduce the cost of drugs for these patients. To reduce financial concerns, charity associations and organizations should increase their donations and raise their spirit by arranging camps, celebrations, and ceremonies.
Ministry of Health should put in place measures to enhance the quality of visits by physicians and healthcare staff and to hold nutritional and self-care training classes.

\section{Conclusion}

The SEIQoL-adapted revealed reasonable lay definitions of QoL in a group of hemodialysis patients. The patients' views of the aspects of life could be used by health policy makers, clinicians, and caregivers as a reliable guide to the most important priorities for treatment and medical interventions.

\section{Acknowledgments}

This study was financed by a grant from the Tabriz University of Medical Sciences (5/53/3166-2014/08/28). We are most grateful for the assistance given by the facilitators, participants, and dialysis staff of Amir-Almomenin Hospital (Mr Jafari and Mrs Seif Ahmadi) in Maragheh, Iran. Professor Tony Warnes of the University of Sheffield (UK) kindly provided advice on the English expression in the paper. We also thank Professor Hamid Allahverdipour for comments that greatly improved the manuscript. Last, but not least, we would like to show our gratitude to Professor Kevin McKee, Dalarna University, who provided insight and expertise that greatly assisted the research.

\section{Disclosure}

The authors report no conflicts of interest in this work.

\section{References}

1. WHOQOL Group. Study protocol for the world health organization project to develop a quality of life assessment instrument (WHOQOL). Qual Life Res. 1993;2:153-159.

2. WHOQOL Group. The world health organization quality of life assessment. Social Sci Med. 1995;41:1403-1409.

3. Tallis K. How to improve the quality of life in patients living with end stage renal failure. RSA. 2005;1(1):18-24.

4. Mittal SK, Ahern L, Flaster E, Mittal VS, Maesaka JK, Fishbane S. Self-assessed quality of life in peritoneal dialysis patients. Am J Nephrol. 2001;21:215-221.

5. Sathvik BS, Parthasarathi G, Narahari MG, Gurudev KC. An assessment of the quality of life in hemodialysis patients using the WHOQOLBREF questionnaire. Indian J Nephrol. 2008;18(4):141-149.

6. Wilkin D, Hughes B. Residential care of elderly people: the consumers' views. Ageing Soc. 1987; 7:175-201.

7. McKee K, Matlabi H, Parker SG. Older people's quality of life and role of home-based technology. Health Promot Perspect. 2012;2(1):1-8.

8. Mckee JK, Parker GS, Elvish J, et al. The quality of life of older and younger people who receive renal replacement therapy. Ageing Soc. 2005;25(6):903-923.

9. O'Boyle CA, McGee HM, Hickey A, et al. The Schedule for the Evaluation of Individual Quality of Life (SEIQoL). Administration Manual. Dublin: Royal College of Surgeons in Ireland. Available from: http:// epubs.rcsi.ie/psycholrep/39/. Accessed May 8, 2016.

10. Mountain LA, Campbell SE, Seymour DG, Primrose WR, Whyte MI. Assessment of individual quality of life using the SEIQoL-DW in older medical patients. Q J Med. 2004;97:519-524. 
11. LeVasseur SA, Green S, Talman P. The SEIQoL-DW is a valid method for measuring individual quality of life in stroke survivors attending a secondary prevention clinic. Qual Life Res. 2005;14:779-788.

12. Hickey AM, Bury G, O’Boyle CA, Bradley F, O'Kelly FD, Shannon W. A new short form individual quality of life measure (SEIQoL-DW): application in a cohort of individuals with HIV/AIDS. BMJ. 1996; 313(7048):29-33.

13. Felgoise SH, Stewart JL, Bremer BA, Walsh SM, Bromberg MB, Simmons Z. The SEIQoL-DW for assessing quality of life in ALS: strengths and limitations. Amyotroph Lateral Scler. 2009; 10(5-6):456-462.

14. Abdel-Kader KH, Myaskovsky L, Karpov I, et al. Individual quality of life in chronic kidney disease: influence of age and dialysis modality. CJASN. 2009;4:711-718.

15. McKee K, Houston D, Barnes S. Methods for assessing quality of life and well-being in frail older people. Psychol Health. 2002;17:737-751.

16. Smith HJ, Taylor R, Mitchell A. A comparison of four quality of life instruments in cardiac patients: SF-36, QLI, QLMI, and SEIQoL. Heart BMJ. 2000;84:390-394.

17. Matlabi H, Parker SG, McKee K. The contribution of home-based technology to older people's quality of life in extra care housing. BMC Geriatr. 2011;31(11):68.

18. Orrell A, McKee K, Torrington J, et al. The relationship between building design and residents' quality of life in extra care housing schemes. Health Place. 2013;21:52-64.
19. Streubert HJ, Carpenter DR. Qualitative Research in Nursing: Advancing the Humanistic Imperative. Philadelphia (PA): Lippincott Williams and Wilkins; 2011:312-363.

20. Yekaninejad MS, Mohammadi Zeidi I, Akaberi A, et al. [Validity and reliability of the kidney disease quality of life - short form in Iranian patients]. J North Khorasan Univ Med Sci. 2012;4(2):261-272. Persian.

21. Himmelfarb J, Ikizler TA. Hemodialysis. N Engl J Med. 2010;363: 1833-1845.

22. Santos RP. Subjective well-being measures of hemodialysis. In: Penido MG, editor. Technical Problems in Patients on Hemodialysis. Rijeka: InTech; 2011:69-86.

23. Bohlke M, Nunes LD, Marini S, Kitamura C, Andrade M, Von-Gysel MP. Predictors of quality of life among patients on dialysis in southern Brazil. Sao Paulo Med J. 2008;126(5):252-256.

24. Wettergren L. Quality of Life in Patients with Malignant Blood Disorders [dissertation]. Stockholm: Karolinska Institute; 2002.

25. Stone PC, Murphy RF, Matar HE, Almerie MQ. Measuring the individual quality of life of patients with prostate cancer. Prostate Cancer Prostatic Dis. 2008;11:390-396. 


\section{Supplementary materials} Information and tips for using and scoring the SEIQoL-adapted scale

\section{Using the SEIQoL-adapted'}

1. I want you to name five things that are very important for your quality of life.

2. Now I want you to say which of these things is the most important for you, ie, which would you put in first place, then second place, and so on.

3. Now I want you to say how satisfied you are with each thing. You can be very satisfied, satisfied, dissatisfied, or very dissatisfied.

Common items important for people's quality of life reported to us included health, family, friends, being independent, getting out and about, doing activities, watching $\mathrm{TV}$, money, etc.

Each item was coded individually and then grouped items together after data to collection.

\section{Scoring the SEIQoL-adapted}

Very satisfied $=4$

Satisfied $=3$

Dissatisfied $=2$

Very dissatisfied $=1$

Some respondents provided answers on one item, some on two, some on three, four, and five. The distribution of the overall quality of life scores for those providing answers to different number of items were all standardized to a range from 25 to 100 . The following score was given to the rank of each item, dependent on how many items participants reported.

If the participants named five items, then the overall score (S) was:

$$
\begin{aligned}
\text { Total score }= & (\text { item } 1 \times \text { satisfaction score }) \\
& +(\text { item } 2 \times \text { satisfaction score }) \\
& +(\text { item } 3 \times \text { satisfaction score }) \\
& +(\text { item } 4 \times \text { satisfaction score }) \\
& +(\text { item } 5 \times \text { satisfaction score })
\end{aligned}
$$

Rank 1 , score $=10$

Rank 2, score $=7$

Rank 3, score $=5$

Rank 4, score $=2$

Rank 5 , score $=1$

$$
\mathrm{S}=10 \times(\mathrm{A})+7 \times(\mathrm{B})+5 \times(\mathrm{C})+2 \times(\mathrm{D})+1 \times(\mathrm{E}),
$$

where $\mathrm{A}, \mathrm{B}, \mathrm{C}, \mathrm{D}$, and $\mathrm{E}$ are the ranks of the five items.
If the participants named four items, then the overall score was:

$$
\begin{aligned}
\text { Total score }= & (\text { item } 1 \times \text { satisfaction score }) \\
& +(\text { item } 2 \times \text { satisfaction score }) \\
& +(\text { item } 3 \times \text { satisfaction score }) \\
& +(\text { item } 4 \times \text { satisfaction score })
\end{aligned}
$$

Rank 1, score $=10$

Rank 2, score $=7$

Rank 3, score $=5$

Rank 4 , score $=3$

$$
\mathrm{S}=10 \times(\mathrm{A})+7 \times(\mathrm{B})+5 \times(\mathrm{C})+3 \times(\mathrm{D}),
$$

where A, B, C, and D are the ranks of the first four items.

If the participants named three items, then the overall score was:

$$
\begin{aligned}
\text { Total score }= & (\text { item } 1 \times \text { satisfaction score }) \\
& +(\text { item } 2 \times \text { satisfaction score }) \\
& +(\text { item } 3 \times \text { satisfaction score })
\end{aligned}
$$

Rank 1 , score $=12$

Rank 2, score $=8$

Rank 3, score $=5$

$$
\mathrm{S}=12 \times(\mathrm{A})+8 \times(\mathrm{B})+5 \times(\mathrm{C}),
$$

where $\mathrm{A}, \mathrm{B}$, and $\mathrm{C}$ are the ranks of first three items.

If the participants named two items, then the overall score was:

$$
\begin{aligned}
\text { Total score }= & (\text { item } 1 \times \text { satisfaction score }) \\
& +(\text { item } 2 \times \text { satisfaction score })
\end{aligned}
$$

Rank 1 , score $=15$

Rank 2, score $=10$

$$
\mathrm{S}=15 \times(\mathrm{A})+10 \times(\mathrm{B}),
$$

where $\mathrm{A}$ and $\mathrm{B}$ are the ranks of the first and second items.

If the participants named one thing that was important for their QoL, then the overall score was:

Total score $=($ item $1 \times$ satisfaction score $)$

Rank 1, score $=25$ 


$$
\mathrm{S}=25 \times(\mathrm{A}),
$$

where A is the rank (between 1 and 4) of item.

For example, if a participant answered three items and were ranked 2 (dissatisfied), 3 (satisfied), and 1 (very dissatisfied), the overall quality of life score would be $\mathrm{S}=12$ (2) $+8(3)+5(1)=53$.

\section{Reference}

1. Matlabi H, Parker SG, McKee K. The contribution of home-based technology to older people's quality of life in extra care housing. $B M C$ Geriatr. 2011;31(11):68.

\section{Publish your work in this journal}

Patient Preference and Adherence is an international, peer-reviewed, open access journal that focuses on the growing importance of patient preference and adherence throughout the therapeutic continuum. Patient satisfaction, acceptability, quality of life, compliance, persistence and their role in developing new therapeutic modalities and compounds to optimize clinical outcomes for existing disease states are major areas of interest for the journal. This journal has been accepted for indexing on PubMed Central. The manuscript management system is completely online and includes a very quick and fair peer-review system, which is all easy to use. Visit http://www. dovepress.com/testimonials.php to read real quotes from published authors.

\footnotetext{
Submit your manuscript here: http://www.dovepress.com/patient-preference-and-adherence-journal
} 